\title{
Impact of Artificial Intelligence on Recruitment and its Benefits
}

\author{
Sri R Lakshmi Manthena \\ Research Scholar \\ Department Commerce and Management Studies \\ Andhra University, Vishakhapatnam
}

\begin{abstract}
In the past, artificial intelligence may have been thought to be a product of science invention; most professionals today understand that the adoption of smart technology is actively changing their jobs. Artificial Intelligence is technologies that makes or recommend actions based on previously collected data.

Today organizations understand the importance of AI; the HR department is not left behind the race. The HR professionals today are focusing to optimize the combination of human and automated work to gain a simple, logical, and automatic work environment. As far as recruitment is concerned there is huge support that AI brings in, especially when you are hiring in volume. AI has helped us in improving the quality of hire and reducing the recruitment error, and it is not just in recruitment but various other functions that are looking at how AI can support their initiatives. In terms of human resources management, artificial intelligence can be applied in many different ways to streamline processes and improve efficiency of the organizational performance, in this competitive business world. To compete with AI, the HR department should re-transfer their workforce in understanding the $\mathrm{AI}$ and its collaboration. $\mathrm{AI}$ is an emerging trend in every organization.

The Main Aim of this study is to critically analyze the impact that Artificial Intelligence (AI) on recruitment in organizations and what are their benefits. The primary data has been collected through a Google form by using likered five point scale questionnaire and forwarded to IT employees, Simple Convenient non probability sampling method is used to secondary data also collected from articles and reports to establish some of the outcomes of the impact of AI on Recruitment. ANOVA One-way is used to compare the artificial intelligence based on recruitment with performance indicating variables namely reliability, such as time \& cost-saving, accuracy, removes partiality, reduced workload, increased productivity, and candidate knowledge. There is a positive association between the recruitment and artificial intelligence.
\end{abstract}

Keywords: Artificial Intelligence, Human Resources Management, Technology, Performance, Organization.

Introduction:

Human resources management mainly deals with Recruitment, Selection, Training \& Development, performance appraisals and encourages the employees to do their best and meet the organizational goals \& objectives. In the process, it maintains the records of employees in the organization, it also keep track of their behavioral patterns due to technological changes made in the organization. It is also the responsibility of every employee to support organizational changes and to achieve organizational goals to succeed in this competitive society.

Artificial Intelligence is a becoming more and more important in organizations, it is a self-learning programs. Some of the organizations do not believe that machines are not sufficient enough for the jobs. Some are afraid of Artificial Intelligence technology implementation in organizations. As further they are come to an extent right, as machines have better abilities to do good job by proper demonstration. Now each organization understands that Artificial Intelligence plays a vital role in recruitment. In 2018 it is noticed that technological trends in $\mathrm{HR}$ are completely reshaped recruitment process in organizations and learn new opportunities according to the market conditions to again competitive advantage.

Now again it is an great opportunity to an organizations to automate the recruitment process and provide best decision making analysis with more detailed information to the recruiters to reduce the operational cost. Artificial intelligence has more specific software which can provide more specific information about the candidate's skills in practice. By the application of Artificial intelligence there is the less scope for manual work, paper work and it makes easy for the HR manager to do the tasks easily.

Recruitment plays very important role in organizational, placing the right person in the right job is difficult task to HR manager and it is an challenging task to HR managers. According to market conditions recruitment creates value to the organization; Artificial intelligence is a tool which uses human intelligence in various fields to improve productivity and performance. AI has massive power to act like a human brain and gives efficient results in recruitment. AI requires certain algorithms and according to that function it performs the better results .so that the reason for AI in Recruitment is the next best thing to be happened in the future. At present if we compare AI to other HR process, it is largely linked with the function of recruitment, and benefited to companies in hiring the right talented with the AI collaboration AI automatically pre -screens the resumes for various companies and gives the information about the applicant based upon the past hiring patterns. 


\section{Literature Review:}

"UweHohgrawe, lead faculty for Northeaster's Master of Professional Studies in Analytics program explains that "we as humans see the information in front of us and use our intelligence to draw conclusions. Machines are not intelligent, but we can make them appear intelligent by feeding them the right information and technology."

Report from Deloittein 2017 notes that 38 percent of survey respondents believed AI would be widely used at their company within three to five years. In 2018, that number rose to 42 percent,. .

Artificial intelligence in recruitment can significantly improve candidate engagement through improved communication between candidates and employers. its system has averaged a 9.8 out of ten on overall candidate experience.

This is because it can provide candidates with updates, feedback and guidance, as well as answer their questions in real-time. This communication - which has a significant impact on candidate experience - is generally lacking,

Geetha R \&BhanuSree Reddy D, "Recruitment through artificial intelligence: A conceptual study" (2018) The major objective of this paper is to study how Artificial Intelligence influences the recruitment strategy. The study also throws light on the techniques used by companies in AI while recruiting.

Ian Bailie Head of HR - "An Examination of Artificial Intelligence and its Impact on Human Resources" (2018) This report tells about big firms that adopt AI and examine the basics of AI and explore how AI is being applied in HR.

\section{Benefits of AI on Recruitment}

HR recruiters are very busy with scheduling interviews, screening candidates, manual tasks. AI can act like a personal assistant to HR recruiters as a goggle assistance the organizations should upload software or automated resume checkers, then the HR recruiters free from their busy schedule. Another great way to automate these unvarying tasks are message service to automating conversations related to specific hiring or job questions, candidates can get the answers they're looking for at any time of the day. By emails or phone calls without reducing the experience of the candidate.

\section{AI Revolutionizing into HR}

Organizations are trying to have more productive HR strategies. And sometimes it is difficult for the people to adopt and learn different AI tool and techniques proficiently which create hurdle in achieving the organizational goal. AI has not only simplified the recruitment process but also changed the way HR works while hiring.

\section{Screening Candidates}

You can use technology to shortlist candidates for a job position. A resume parser extracts data from the candidate's resume and makes the info available in data fields. Hire smarter and make candidate selection automated using this automation tool.

\section{Matching Candidates}

Get quality recommendations matching a resume or job description. Match technologiesunderstand the difference between job description and candidate, so it allows you to find excellent candidates quickly. It provides the best fit through synonym matches related to the domain, skills, tools, location, education, etc.

\section{Resume Enrichment}

Get updated information about the candidates through their social profiles. You can also visit a marketplace and get all the information you need from the email ID of a candidate.

\section{Conceptual framework}

HR recruiters are very busy with scheduling interviews, screening candidates, manual tasks if they implemented Artificial intelligence in recruitment, what are the benefits they are having and how it will be successful in the organization.

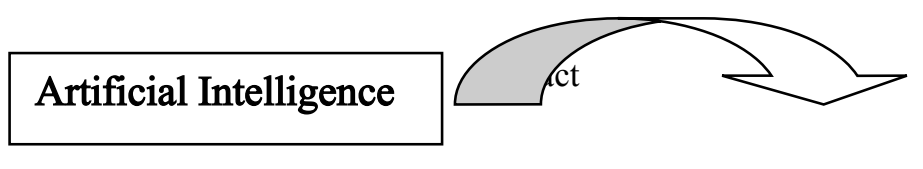
Recruitment
1. It saves Time
2. Remove Bias
3. Right Person
4. Improve Candidate's Experience

If Alis implemented in recruitment in organizations the of recruiters time will save, no scope for bias a, man can make mistakes but machine cannot do mistakes, so right person will be placed in the right job by the usage of AI in recruitment with this the productivity will increases with better quality. This can be achieved by implementing artificial intelligence in human resource recruitment.

The variable chosen here is
1. Quality
2. Optimization
3. Accuracy
4. Paperless
5. Productivity 


\section{Research Methodology}

\section{Objectives of the study:}

1. To identify the impact of AI on Recruitment.

2. To understand the impact of AI on Recruitment and its benefits.

\section{Research Type:}

Descriptive research is used for this study to amylase the objectives

\section{Sample}

Non probability sampling method is used to collect the primary data

\section{Collection of Data:}

To analyze the study and investigation purpose, data is important, for this study both primary and secondary data have been collected

\section{Primary data}

Primary data was collected by forwarding goggle form to the respondents by using non probability simple sampling method. The goggle forms forwarded to Managers, Recruiters and Employees to know the function of Artificial intelligence in Recruitment SecondaryData:

Secondary data also collected for this study from various journals, mazines and news to know their contributions about study.

\section{Demographics Factors}

\section{DATA ANYLSIS}

\begin{tabular}{|l|c|c|}
\hline Age(years) & Frequency & Percentage \\
\hline $22-25$ & 15 & 21.4 \\
\hline $26-30$ & 13 & 18.5 \\
\hline $31-40$ & 25 & 35.7 \\
\hline Above 40 & 17 & 28.5 \\
\hline
\end{tabular}

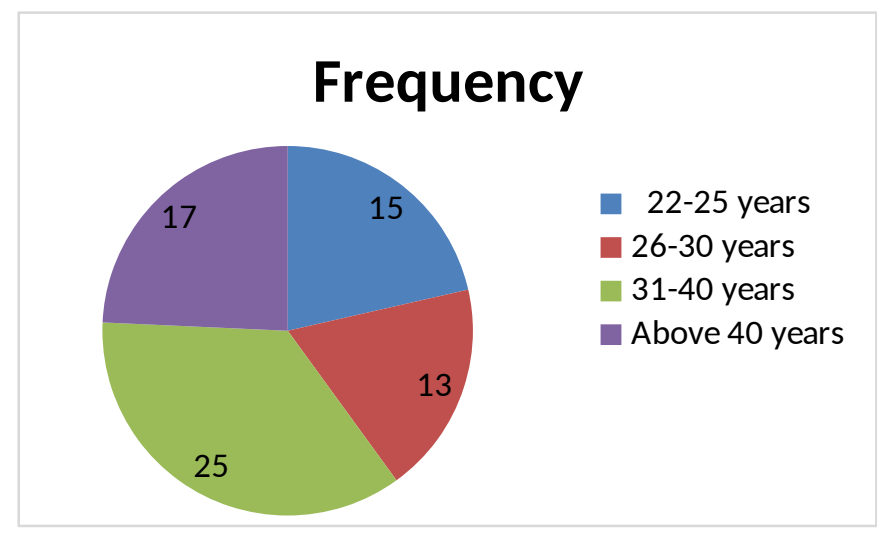

Interpretation: Form the above table it is interpreted the age group of respondent involved for this study

\begin{tabular}{|l|c|c|}
\hline Gender & Frequency & Percentage \\
\hline Male & 48 & 68.5 \\
\hline Female & 22 & 31.4 \\
\hline
\end{tabular}

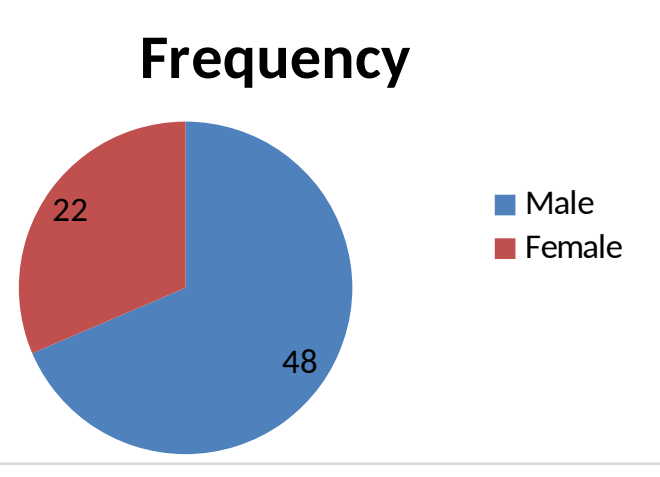


Here both male and female are considered for this study

\begin{tabular}{|l|c|l|}
\hline Marital Status & Frequency & Percentage \\
\hline Single & 28 & 40 \\
\hline Married & 42 & 60 \\
\hline
\end{tabular}

\section{Frequency}

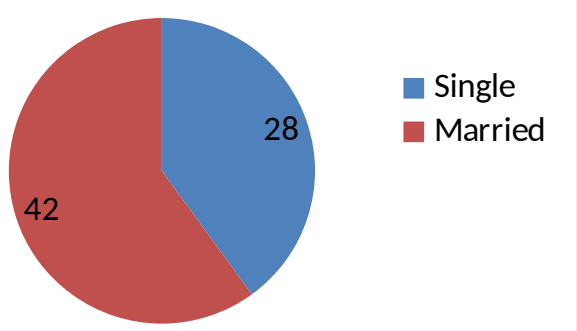

Even their martial status also consider for this study

Work Experience

\begin{tabular}{|l|c|c|}
\hline Years & Frequency & Percentage \\
\hline Less than 2 years & 29 & 41.4 \\
\hline $2-5$ years & 22 & 31.4 \\
\hline 6-10 years & 11 & 15.7 \\
\hline $11-15$ years & 8 & 11.4 \\
\hline
\end{tabular}

\section{Frequency}

8
11

Depending upon the experience of the respondent the study is conducted

Educational Qualification

\begin{tabular}{|l|l|l|}
\hline Qualification & Frequency & Percentage \\
\hline Doctoral Degree & 1 & 1.42 \\
\hline Master"s Degree & 11 & 15.71 \\
\hline Bachelor"s Degree & 32 & 45.7 \\
\hline Diploma & 15 & 21.4 \\
\hline Others & 10 & 14.2 \\
\hline
\end{tabular}

\section{Frequency}

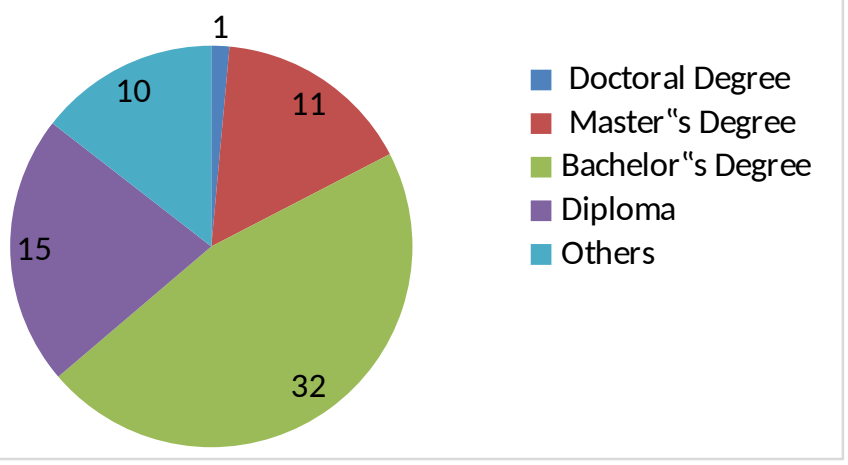


Designation

\begin{tabular}{|l|l|l|}
\hline Designation & Frequency & Percentage \\
\hline Administrator & 23 & 32.8 \\
\hline Business and Program Analyst & 15 & 21.4 \\
\hline Engineer(Automation \&Software) & 15 & 21.4 \\
\hline Project and HR manager & 10 & 14.2 \\
\hline Managing Director & 1 & 1.4 \\
\hline Others & 6 & 8.5 \\
\hline
\end{tabular}

\section{Frequency}

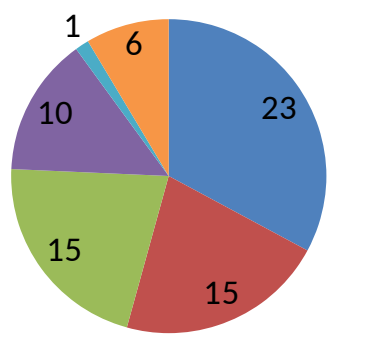

$$
\begin{array}{ll}
\text { Administrator } & \begin{array}{l}
\text { Business and Program Ana- } \\
\text { lyst }
\end{array} \\
\begin{array}{ll}
\text { Engineer(Automation } & \text { Project and HR manager } \\
\text { \&Software) } & \\
\text { Managing Director } & \text { Others }
\end{array}
\end{array}
$$

Designation of the respondent play's very important role for this study, depending upon their designation the implementation of $\mathrm{AI}$ in Recruitment data is collected accurately

\begin{tabular}{|c|c|c|c|c|}
\hline Groups & Count & Sum & Average & Variance \\
\hline AI to attract potential candidates. & 5 & 70 & 14 & 17.5 \\
\hline AI to improve the recruiter's response time. & 5 & 70 & 14 & 42.5 \\
\hline AI to discover new talents quickly. & 5 & 70 & 14 & 17.5 \\
\hline AI to filter resumes & 5 & 70 & 14 & 80 \\
\hline AI to perform processes without human intervention. & 5 & 70 & 14 & 17.5 \\
\hline AI to reduce administrative workload & 5 & 70 & 14 & 49.5 \\
\hline AI to replace manual tasks. & 5 & 70 & 14 & 65 \\
\hline AI to substitute repetitive tasks. & 5 & 70 & 14 & 97 \\
\hline AI to avoid errors automatically. & 5 & 70 & 14 & 84.5 \\
\hline AI to convert resources efficiently & 5 & 70 & 14 & 61 \\
\hline AI to transform inputs into outputs with high quality. & 5 & 70 & 14 & 17.5 \\
\hline AI in a cost-effective manner. & 5 & 70 & 14 & 41.5 \\
\hline AI to improve productivity. & 5 & 70 & 14 & 92 \\
\hline AI to speed working processes & 5 & 70 & 14 & 135 \\
\hline AI functions easily. & 5 & 70 & 14 & 110.5 \\
\hline AI to complete tasks with minimal supervision & 5 & 70 & 14 & 84 \\
\hline AI to simplify complex tasks. & 5 & 70 & 14 & 78.5 \\
\hline
\end{tabular}

Hypothesis of the study:

To analyze the objectives, two hypothesis are framed null and alternative

Null hypothesis: (Ho) There is a no significant impact of Artificial Intelligence on Recruitment.

Alternative Hypothesis: (H1) There is a significant impact of Artificial Intelligence on Recruitment

Anova: Single Factor

SUMMARY 


\begin{tabular}{|l|r|r|r|r|r|r|}
\hline \multicolumn{1}{|c|}{ Source of Variation } & \multicolumn{1}{c|}{ SS } & \multicolumn{1}{c|}{$d f$} & \multicolumn{1}{c|}{ MS } & $F$ & P-value & \multicolumn{1}{c|}{$F$ crit } \\
\hline Between Groups & 0 & 16 & 0 & 0 & 1 & 1.794556 \\
\hline Within Groups & 4364 & 68 & 64.17647 & & & \\
\hline & & & & & & \\
\hline Total & 4364 & 84 & & & & \\
\hline
\end{tabular}

From the above data analysis it was observed that the null hypothesis which was assumed for the study was rejected and alternative hypothesis is accepted "There is a significant impact of Artificial Intelligence on Recruitment" and the organizations will also be benefited by implementing the artificial intelligence (AI) in recruitment 1) Quality 2 ) Optimization 3) Accuracy 4) Paperless 5) Productivity .It also proven that if organization are implenting AI in HRM for Recruitment the 1.Quality of candidates will apply for the job

2. Optimization techniques can be used to reduce cost

3. Accuracy: Accurate Employability will takes place in organization

4. Paperlesswork will be used for recruitment to save time and money

5. Productivitywill obviously increase with talented pool of candidates into organization to through AI usage in Recruitment.

\section{Findings and Conclusion}

In today's era, recruiter think AI technology is increasing area in HRM. With the rapidly emerging trend of utilizing AI technologies in the organization environment in the last twenty years the recruitment and selection strategy of the HR management will gradually incorporate more AI solutions into its process. Artificial intelligence is a technology which can work smartly as equal to human brain in different situations. It gains attention and importance in automating recruiting system when compared to traditional recruitment methods. By using AI software in the traditional recruitment process a company could possibly see results in their communication with candidates, larger candidate pool, rediscovery of lost talents and overall improved recruitment results .Recruitment is the central activity of all organization to work on. AI is believed to be able to replace administrative tasks in both HRM but also especially within the recruitment process in the recruitment activities, intervening job applicant variable and the recruitment results.

\section{References:}

[1] Board Chair Authentic Leadership and Nonexecutives Motivation and Co, by Guerrero, S. Lapal- 2015

[2] Collaborating to create The Internet as a platform for customer engag by Mohanbi-2005

[3] Evolution and Evaluation of Human Resources Function in India A Bala, by Rao, T. V.- 2014

[4] Factors that influence new generation candidates to engage with and co by va-2019

[5] Ideas and concepts on the Hungarian information economy by Jzse-1988

[6] Intelligent capitalism and the disappearance of labourWhithert by Wei-2018

[7] Melder, B. (2018) the Role of Artificial Intelligence (AI) in Recruitment.

[8] Modelling recruitment dynamics of hake, Merlucciusmerluccius, in the by V-2008

[9] . Paying pharmacists for patient care A systematic review of remunerat, by Houle, S. K. D. Gr- 2014

[10] https://www.talentlyft.com/en/blog/article/207/the-role-of-artificial-intelligence-aiinrecruitment 